\title{
O EN SINO DE FÍSICA DAS RADIAÇÕES NA FORMAÇÃO DE AUXILIARES DE ENFERMAGEM E ATEN DENTES DE CONSULTÓRIOS ODONTOLÓGICOS: SONDAGEM DE CONCEPÇÕES SOBRE OS RAIOS-X COM ENFOQUE NA PREVENÇÃO E TECNOLOGIA
}

Luciano Gonsalves Costa ${ }^{1}$

Ana Paula Astrath Costa ${ }^{2}$

\begin{abstract}
Resumo: N este trabalho é feita uma reflexão sobre al gumas questões que envolvem a formação e a atuação do auxiliar de enfermagem e do atendente de consultório odontológico num contexto marcado pela tecnologia. A educação científica e a alfabetização científica são apontadas como caminhos para a transformação do cenário existente. Também, são apresentados os resultados de uma investigação conceitual sobre os raios- $x$ com enfoque na prevenção e tecnologia.
\end{abstract}

Unitermos: Educação em Saúde; Educação Científica; Ensino de Física; Alfabetização Científica.

Abstract: This paper presents some considerations about the technology and the formation of nursing and dentist staff. The scientific education and the scientific literacy are pointed out as alternatives for the trans formation of the scenery. Finally, the results of a conceptual research about x-rays are presented.

Keywords. Health Education; Scientific Education; PhysicsTeaching; Scientific Literacy.

\section{Introdução}

O século XX testemunhou, incontestavelmente, um acúmulo de conhecimento científico e tecnológico sem precedentes na história da humanidade. A C iência e a T écnica penetraram profundamente no cotidiano das pessoas e nos diferentes setores do sistema produtivo, dinamizando e tornando seus processos mais eficientes e menos dispendiosos ${ }^{3}$. Um modo de reconhecer 0 impacto desses conhecimentos sobre a sociedade é observando a realidade imediata, o entorno.

Convivemos com as mais diversas tecnologias e a cada dia surgem descobertas científicas que, certamente, continuarão a influenciar-nos. Em especial, vejamos o caso da saúde pública. A história mostra que desde os primórdios da civilização moderna este tem sido um campo fortemente influenciado pelo conhecimento acumulado nos diversos ramos da ciência, das ciências humanas às ciências naturais, ademais, no plano individual, em qualquer momento é provável testemunharmos a tecnologia auxiliando seus profissionais do diagnóstico ou prognóstico mais preciso à ação preventiva.

\footnotetext{
1 Professor Assistente M estre do Departamento de Física da Universidade Estadual de Maringá, Paraná, Brasil. D outorando do Programa de Pós-Graduação em Informática na Educação da U niversidade F ederal do Rio Grande do Sul, Porto Alegre, Rio G rande do Sul, Brasil. (email: Iuciano@dfi.uem.br).

2 Professora de Ciências da Rede M unicipal de Ensino de M aringá, Paraná, Brasil.

${ }^{3} \mathrm{~N}$ ão obstante, é mister um olhar crítico sobre as conseqüências do avanço científico e tecnológi co sobre as condições de existência da vida e do planeta. É importante que etejamos atentos, nunca relegando a planos secundários o aprendizado extraído de testemunhos dados pela civilização que indicam a insuficiência do crescimento científico na condução à liberdade, ao aperfeiçoamento da sociedade, enfim, ao progresso da humanidade; do mesmo modo que o ideário iluminista de progresso fracassou com o advento da Revolução Industrial, esse tipo de ilusão continua frustrada diante do aumento da fome, da mi séria e das desigualdades sociais.
} 
Entretanto, apesar da possibilidade dessa gama de conhecimento contribuir para a melhoria da condição de existência da vida, por um lado, as lacunas decorrentes da incompreensão de determinados fatos científicos e dos fundamentos de seus derivados tecnológicos, acrescidas da ação dogmática e da práxis equivocada, por outro, apresentam-se como enormes obstáculos à sua concretização ${ }^{4}$.

Logo, uma vez que o estabelecimento de padrões e a redefinição de exigências e necessidades no moderno mundo do trabal ho têm reflexos no âmbito da sua educação, a aprendizagem insuficiente pode tornar a manipulação e o contato com a tecnologia algo extremamente nocivo ao bem-estar humano. Particularmente, recordemo-nos do mais grave acidente radioativo ocorrido no país: a tragédia foi originada do irresponsável abandono de uma bomba de césio-137 num hospital desativado, semidestruído, na cidade de G oiânia, na década de 80 (Cruz, 1987; C andotti et al., 1988).

Por isso, tendo em vista a necessidade do desenvolvimento de outro tipo de práxis nesse cenário marcado pelo senso científico, a educação científicas (Penick, 1998; Vale, 1998) pode contribuir para com a efetiva promoção do entendimento do fenômeno científico e de seus impactos sobre o entorno no plano da educação em saúde. I gualmente, a despeito das contradições presentes no tradicional ensino das ciências naturais praticado (ausência da experimentação, matematização excessiva, a-historicidade dos conteúdos, currículos descontextualizados, etc.), o ensino de física pode desempenhar um papel instrumental importante no processo de alfabetização científica do profissional da saúde.

No âmbito da física contemporânea, a saúde pública é o campo que mais foi beneficiado pela descoberta dos raios-x ( $M$ artins, 1998; N eves et al., 2000) por intermé dio de suas tecnologias, especialmente a medicina e a odontologia. Todavia, isto necessariamente não significa que seus profissionais têm sido formados suficientemente e operado neste contexto de forma inequívoca; sem muito rigor, é o que sugere a avaliação de currículos institucionais e de conhecimentos e condutas de auxiliares de enfermagem e atendentes de consultórios odontológicos quando se trata desse fenômeno.

D e fato, este panorama sinaliza a incapacidade do sistema de formação em voga em contribuir para a superação dos desafios e proposição de soluções para as questões enfrentadas no campo da saúde pública. Portanto, é uma realidade que urge uma transformação.

$N$ este sentido, na tentativa de obter subsídios para que se possa repensar o ensino de física das radiações eletromagnéticas para auxiliares de enfermagem e atendentes de consultó-

\footnotetext{
${ }^{4}$ Andrea Vesalio (Vesalio apud N eves, 1999, p. 64), em 1543, numa passagem de De corporis humani fabrica, ao retratar a saúde pública da primeira metade do século XVI, apresenta um quadro que muito se assemelha ao atual. A análise do referido trecho indica que o desvirtuamento ao qual a prática da ciência e, conseqüentemente, o seu ensino foram submetidos não é al go recente. Apesar do longínquo momento histórico, o "desabafo" de Vesalio é muito atual ao instigar a reflexão mais ampla a respei to das questões que envolvem o binômio ciência-educação. H á tempos tem-se convivido com "escravos" mal-instruídos e "doutos" mal-formados. Ainda, o mais assombroso é que esse convívio tem ocorrido a despeito do impacto provocado pela publicação, também em 1543, do livro D e revolutionibus orbium coelestium de N i colau Copérnico; a publicação da obra de Copérnico (Copérnico, 1984) é o marco da grande virada ocorrida na ciência, a "Revolução Científica", que dá início à Ciência M oderna. Assim, a ciência e a educação como um todo têm sido vítimas da ação equivocada realizada em seus âmbitos.

${ }^{5}$ Tanto a educação científica quanto a alfabetização científica são processos que não só envolvem a aquis ção do conhe cimento acumulado pelas Ciências, mas que também contribuem para a formação de indi víduos autônomos e capazes de perceber a dimensão histórica dos problemas enfrentados pela sociedade (outrossim, capazes de compreender a sua situação e a sua própria história!), e que se empenhem na superação dos mesmos e etejam atentos às exi gências e necessidades do seu contexto e momento histórico.
} 
rios odontológicos (ACD ), apresentamos os resultados de uma investigação conceitual ${ }^{6}$ sobre os raios-x com enfoque na prevenção e tecnologia.

\section{C onsiderações metodológicas}

A investigação ocorreu no $2^{\circ}$ semestre de 2000 e envolveu uma turma composta de 39 estudantes matriculados num curso de formação de "auxiliar de enfermagem" a cargo de um estabelecimento privado de ensino profissionalizante.

0 recurso utilizado para o mapeamento das concepções/condutas foi o questionário ${ }^{7}$. 0 questionário era composto de seis questões dissertativas onde os estudantes, anônima e individualmente, registraram as respostas. A finalidade das questões éfazer com que os sujeitos recorram às experiências (escolares, profissionais, etc.) relacionadas com as radiações ${ }^{8}$ para, então, podermos estudar as tendências das respostas e os comportamentos relatados de uma forma absolutamente dependente desse fator. As questões envolviam: a) a conceituação e caracterização dos raios- $x$; b) o conhecimento de fontes e aplicações dos raios- $x$; c) o conhecimento de efeitos da radiação e noções de dosimetria e segurança/proteção radiológica; ainda, d) o conhecimento de fatos e episódios que se relacionam com 0 uso das radiações.

\section{Resultados}

A análise das respostas indica que:

a) $\mathbf{3 0 , 8} \%$ dos entrevistados afirmaram nada saber a respeito do fenômeno $(5,1 \%)$ ou simplesmente não responderam $(25,7 \%) ; \mathbf{5 8 , 9 \%}$ das respostas associaram o fenômeno ao radiodiagnóstico e apenas 10,3\% continham informações adequadas sobre esse tipo de radiação;

b) $5,1 \%$ dos entrevistados associaram as fontes de raios- $x$ à estabelecimentos médicos (neste caso, clínicas de radiodiagnóstico), 82,1\% afirmaram desconhecêlas $(56,4 \%)$ ou simplesmente nada responderam $(25,7 \%)$ e $\mathbf{1 0 , 8} \%$ das respostas foram redundantes;

c) $\mathbf{7 6 , 9 \%}$ dos entrevistados desconhecem as aplicações dos rai os- $x(20,5 \%)$ ou não responderam a questão $(56,4 \%) ; \mathbf{5 , 1} \%$ das respostas foram adequadas e $\mathbf{1 8 , 0 \%}$ redundantes (radioterapia, quimioterapia, ultrassonografia, raio-laser e eletrocardiograma);

d) $\mathbf{2 5 , 6 \%}$ das respostas têm relação com o conhecimento geral acerca dos possíveis danos causados pela radiação - malformações fetais (12,8\%), câncer $(7,7 \%)$ e morte $(5,1 \%)$; por outro lado, $\mathbf{2 , 6 \%}$ dos entrevistados mencionaram a impotência sexual bem como outros $2,6 \%$ o surgimento de "ponto duplo nos fios de cabelo" como efeitos da radiação; ainda, $69,2 \%$ dos entrevistados não responderam a questão (12,8\%), nada mencionaram (10,2\%) ou afirmaram desconhecer fatos correlatos às possíveis implicações do uso dos raios-x no organismo humano $(46,2 \%)$;

\footnotetext{
6 " 'Concè to' é utilizado em sua significação mais ampla de idéia ou noção geral acerca de al go." (M ohr, 2000, p. 90). 70 ato de responder questões pode estimular significati vamente a atividade de reflexão (Petry et al., 1994), auto-estudo e auto-conhecimento (M oreira, 1997).

${ }^{8}$ Como hipótese de trabalho, também consideramos relevante o patrimônio cognitivo trazido pelo sujeito que, construído a partir da interação com a realidade, representa sua compreensão do mundo.
} 
e) As respostas revelaram que a grande maioria dos entrevistados, $\mathbf{9 7 \%}$, ainda não atua ou não têm experiência profissional em estabelecimentos de radiodiagnóstico; os demais 3\% dos entrevistados nada indicaram no questionário. Cabe destacar que apenas $\mathbf{7 , 7 \%}$ dos entrevistados mencionaram 0 fato de devermos nos submeter à exames dessa natureza apenas quando realmente necessário;

f) Apenas $\mathbf{1 0 , 3 \%}$ das respostas apresentadas relacionaram dose de radiação com caso clínico ou local (do organismo) de exposição/irradiação, os outros $\mathbf{8 9 , 7 \%}$ eram tão confusas a ponto de podermos desconsiderá-las enquanto objeto de análise;

g) As respostas revelam que apenas $5,1 \%$ dos entrevistados têm consciência da utilização da proteção de chumbo (colete) e da blindagem do ambiente de radiodiagnóstico como mei os de proteção; ainda, 2,6\% afirmaram que o colete é utilizado para se "evitar complicações com a pele" e 10,3\% mencionaram a "fuga" do responsável pela irradiação desse ambiente como uma estratégia de segurança. As demais respostas puderam ser desconsideradas ou não constavam nos questionários.

\section{D iscussão e considerações finais}

0 s resultados verificados apontam para o desconhecimento e para a incompreensão do fenômeno e dos seus conceitos. Diversos fatores podem contribuir para caracterizar 0 quadro encontrado. Contudo, a constatação deve estar fortemente relacionada com a qualidade do ensino de ciências naturais, e das ciências como um todo, que vem sendo praticado na escola de nível fundamental e médio. 0 que, aliás, não é uma característica exclusiva deste tipo de ensino ou escola, ou mesmo do século XX.

Diante da realidade educacional no país, tem havido uma incessante busca por estratégias de ensino na expectativa de que suas aplicações contribuam para a diminuição das carências formativas de caráter básico apresentadas pelos educandos. Em particular, acreditamos que as carências constatadas poderão ser amenizadas se houver uma preocupação maior em se estimular o raciocínio conceitual (desenvolvimento de concepções nãocientíficas presentes, melhoria da compreensão de conceitos científicos existentes, ou formação de conceitos científicos inexistentes), visto que sem conceitos claros qualquer atividade não tem valor algum ou não passa apenas de uma manipulação de "objetos". Ainda, na tentativa de fazer com que 0 aprendiz se identifique com a atividade, consideramos igualmente importante a necessidade da aproximação dos conceitos da sua realidade profissional, o que potencialmente pode produzir um "choque" de interesses, pois, por conhecer de forma coerente, passará a questionar o que vinha fazendo e como deverá fazer, sentindo-se motivado a produzir o seu conhecimento sobre 0 apresentado.

$\mathrm{N}$ este aspecto, além de se considerar tais apontamentos, ao se desenvolver uma metodologia de ensino, apoiada nas possibilidades de uma abordagem mais próxima da realidade do fenômeno científico, quando se empreende a educação científica e o raciocínio conceitual, de modo a se relacionar os aspectos de prevenção e tecnológicos da física das radiações - principalmente a física dos raios- $x$ - , poderá se possi bilitar a atuação consciente desses profissionais da saúde. 


\section{Referências bibliográficas}

CAN D OTTI, E. et al. É preciso não esquecer G oiânia. Ciência H oje, Suplemento, São Paulo, v. 7, n. 40, mar. 1988.

CARVALH O , J.M . 0 processo de construção do conhecimento no ensino superior e as novas exigências do mundo do trabalho. In: . (O rg.). M etodologia do ensino superior. Vitória: UFES, 1998. p. 15-26.

CO PÉRN ICO , N . As revoluções dos orbes celestes. Lisboa: Fundação C alouste Gulbenkian, 1984.

CRUZ, F.F.S. Radioatividade e 0 acidente de G oiânia. Caderno Catarinense de Ensino de Física, v. 4, n. 3, p. 164-169, dez. 1987.

M ART IN S, R.A. A descoberta dos raios-x: o primeiro comunicado de Röntgen. Revista Brasileira de Ensino de Física, v. 20, n. 4, p. 373-391, dez. 1998.

M O HR, A. Análise do conteúdo de "saúde" em livros didáticos. Ciência \& Educação, v. 6, n. 2, p. 89-106, 2000.

M O REIRA, M .A. M apas conceituais e aprendizagem significativa. M imeo. 1997.

NEVES, M .C.D. et al. Fantasies, myths and fallacies in modern physics teaching: the case of the 3 "R" (radioactivity, relativity, red-shifts). Ciências Exatas e N aturais, Guarapuava, v. 1, n. 2, p. 103-110, jan./jun. 2000.

N EVES, M .C.D. M emórias do invisível: uma reflexão sobre a história no ensino de física e a ética da ciência. M aringá: LCV/REN O P, 1999.

PEN ICK, J.E. Ensinando "alfabetização científica". Educar em Revista, v. 14, p. 91-113, 1998.

PET RY, P.P. et al. Entrevistando com o método clínico para saber sobre o método clínico: um estudo das hipóteses dos professores sobre o seu trabalho. In: BRASIL. M inistério da Educação. Informática na escola: pesquisas e experiências. Braślia: M EC/SEM TEC, 1994. p. 174-177.

VALE, J.M .F. Educação científica e sociedade. In: N ARDI, R. (O rg.) Q uestões atuais no ensino de ciências. São Paulo: Escrituras, 1998. p. 1-7. (Série Educação para a Ciência, v. 2).

\section{Artigo recebido em março de 2001 e selecionado para publicação em setembro de 2002.}

